\title{
Unlocking the potential of $p$-doped hole transport layers in inverted organic light emitting diodes
}

\author{
Jin Song, Dashan Qin,* Yuhuan Chen, Wenbo Wang, and Li Chen
}

\begin{abstract}
.
The $\mathrm{MoO}_{3}$ doped N,N'-bis-(1-naphthl)-diphenyl-1,1'-biphenyl-4,4'-diamine (NPB: $\mathrm{MoO}_{3}$ in 2:1 mass ratio) and 4,4'-N,N'-dicarbazole-biphenyl (CBP: $\mathrm{MoO}_{3}$ in 2:1 mass ratio) as $p$-doped hole transport layers have been used in inverted organic

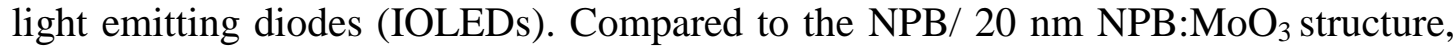
the NPB/ $10 \mathrm{~nm}$ CBP: $\mathrm{MoO}_{3} / 10 \mathrm{~nm}$ NPB: $\mathrm{MoO}_{3}$ structure showed increased device performance, mostly because the hole transport barrier from $\mathrm{CBP}: \mathrm{MoO}_{3}$ to NPB was smaller than that from NPB: $\mathrm{MoO}_{3}$ to NPB; it also presented improved device performance than the NPB/ $20 \mathrm{~nm} \mathrm{CBP}: \mathrm{MoO}_{3}$ structure, ascribed to the higher conductivity of NPB: $\mathrm{MoO}_{3}$ than that of $\mathrm{CBP}: \mathrm{MoO}_{3}$. We provide a manageable way to unlock the merits of $p$-doped hole transport layers for markedly increasing the performance of IOLEDs.
\end{abstract}

Keywords: inverted OLEDs, $p$-doped hole transport layers, transport barrier, hole conduction 


\section{Introduction}

Inverted organic light emitting diodes (IOLEDs) have attracted much attention, due to their compatibility with n-channel amorphous silicon field-effect transistor, favoring the low-cost production of active-matrix flat-panel display [1-10]. However, in order to compete with the conventional liquid crystal display, the active-matrix OLED display needs to be more efficient, stable, and cheaper. Thus, it is of an urgent need for OLEDs to reduce the power loss as much as possible, which has been considered as a fundamental issue for LEDs.

The improvement of hole injection can contribute to the reduction in the power loss of OLEDs. During the past decade, $p$-doped hole transport layers (HTLs) have been widely used to enhance hole injection of OLEDs [11-13], since (1) the $p$-doped HTL can offer ohmic contacts with metal even with medium work function, e.g., Al, as a result of the thin depletion zone formed between $p$-doped HTL and metal, and (2) the $p$-doped HTL can lead to the significant decrease in ohmic loss during hole conduction relative to the undoped HTL. The $\mathrm{MoO}_{3}$ doped N,N'-bis-(1-naphthl)-diphenyl-1,1'-biphenyl-4,4'-diamine (NPB: $\mathrm{MoO}_{3}$ ) and4,4'-N,N'-dicarbazole-biphenyl $\left(\mathrm{CBP}: \mathrm{MoO}_{3}\right)$ are among the most frequently employed $p$-doped HTLs. As shown in Fig. 1, the highest occupied molecular orbital (HOMO) levels for NPB: $\mathrm{MoO}_{3}$ and $\mathrm{CBP}: \mathrm{MoO}_{3}$ are -5.35 and $-6.25 \mathrm{eV}$; the work functions for NPB: $\mathrm{MoO}_{3}$ and $\mathrm{CBP}: \mathrm{MoO}_{3}$ are 4.9 and $5.6 \mathrm{eV}[14,15]$, respectively.

In conventional $p$ - $i-n$ OLEDs, a single $p$-doped HTL has been used. Despite achieving the remarkable device performance, the usage of a single $p$-doped HTL is currently stick in a dilemma that the hole conduction advantage of $p$-doped HTL is unavoidably counteracted by the hole transport barrier $\left(\phi_{\mathrm{B}}\right)$ across the interface with the undoped HTL [16-18]. As of now, how to unlock the potential of $p$-doped HTLs remains still challenging in IOLEDs. In this paper, for the first time, the combination of two $p$-doped HTLs has been applied to improve the performance of IOLEDs, and the underlying mechanism was discussed.

\section{Experimental}

$100 \mathrm{~nm}$-thick ITO thin film coated glass substrates were commercially bought 
with a sheet resistance of $10 \Omega$ per square. After being carefully cleaned in acetone, alcohol, and de-ionized water sequentially by an ultrasonic horn, the pre-patterned ITO substrates were blown dry by a nitrogen gun. The NPB, CBP, bathocuproine (BCP), and tris(8-quinolinolato) aluminum (Alq3) were obtained from Jilin OLED material Company; the $\mathrm{MoO}_{3}$ and $\mathrm{Li}_{2} \mathrm{CO}_{3}$ were purchased from Sigma-Aldrich Company, and applied as p- and n-typed dopants, respectively. The ratios of dopant to host were recorded in mass. All the materials were used as received.

The base pressure of the device fabrication was $4 \times 10^{-4} \mathrm{~Pa}$. The five IOLEDs were fabricated as follows:

IOLED 1: ITO/ 4:1 BCP:Li $\mathrm{CO}_{3} 10 \mathrm{~nm} / \mathrm{Alq} 340 \mathrm{~nm} / \mathrm{NPB} 60 \mathrm{~nm} /$ 2:1 NPB: $\mathrm{MoO}_{3} 20 \mathrm{~nm} / \mathrm{Al}$;

IOLED 2: ITO/ 4:1 BCP: $\mathrm{Li}_{2} \mathrm{CO}_{3} 10 \mathrm{~nm} / \mathrm{Alq} 340 \mathrm{~nm} / \mathrm{NPB} 60 \mathrm{~nm} /$

2:1 CBP: $\mathrm{MoO}_{3} 20 \mathrm{~nm} / \mathrm{Al}$;

IOLED 3: ITO/ 4:1 BCP: $\mathrm{Li}_{2} \mathrm{CO}_{3} 10 \mathrm{~nm} / \mathrm{Alq} 340 \mathrm{~nm} / \mathrm{NPB} 60 \mathrm{~nm} /$

2:1 CBP: $\mathrm{MoO}_{3} 10 \mathrm{~nm} / 2: 1 \mathrm{NPB}: \mathrm{MoO}_{3} 10 \mathrm{~nm} / \mathrm{Al}$;

IOLED 4: ITO/ 4:1 BCP:Li $\mathrm{CO}_{3} 10 \mathrm{~nm} / \mathrm{Alq} 340 \mathrm{~nm} / \mathrm{NPB} 60 \mathrm{~nm} /$

2:1 CBP: $\mathrm{MoO}_{3} 5 \mathrm{~nm} /$ 2:1 NPB: $\mathrm{MoO}_{3} 15 \mathrm{~nm} / \mathrm{Al}$;

IOLED 5: ITO/ 4:1 BCP:Li $\mathrm{CO}_{3} 10 \mathrm{~nm} / \mathrm{Alq} 340 \mathrm{~nm} / \mathrm{NPB} 60 \mathrm{~nm} /$

2:1 CBP: $\mathrm{MoO}_{3} 15 \mathrm{~nm} /$ 2:1 NPB: $\mathrm{MoO}_{3} 5 \mathrm{~nm} / \mathrm{Al}$.

Note that, The 2:1 doping ratio of organic material to $\mathrm{MoO}_{3}$ was an optimized value $[19,20]$. It should be stressed that some part of $\mathrm{MoO}_{3}$ degraded into lower valance oxides in the vacuum deposition, but for simplifying the device expression, $\mathrm{MoO}_{3}$ was used as the nominal notation.

The current versus voltage $(I-V)$ characteristics of the OLEDs were measured by the programmable Keithley 2400 sourcemeter, and the luminance was recorded by an ST-86LA Spot Photometer under the ambient condition.

\section{Results and discussion}

\subsection{The performance comparisons of the IOLEDs 1-3}

Fig. 2(a) shows the $I-V$ characteristics for these three devices. At a given driving voltage $\geq 4 \mathrm{~V}$, there was a decrease of current density in the order of IOLED $3>$ IOLED $2>$ IOLED 1.At a driving voltage of $9 \mathrm{~V}$, the current densities of the IOLEDs 1-3 were 
$47.5,140.0$, and $384.3 \mathrm{~mA} / \mathrm{cm}^{2}$, respectively. It demonstrates that the combination of $10 \mathrm{~nm}$ 2:1 CBP: $\mathrm{MoO}_{3}$ and $10 \mathrm{~nm}$ 2:1 NPB: $\mathrm{MoO}_{3}$ outperformed the individual $20 \mathrm{~nm}$ 2:1 NPB: $\mathrm{MoO}_{3}$ and CBP: $\mathrm{MoO}_{3}$ in terms of generating hole current in to the NPB. As shown in Fig. 2(b), at a given driving voltage $\geq 4 \mathrm{~V}$ there was a decrease of luminance in the order of IOLED $3>$ IOLED $2>$ IOLED 1 . At a driving voltage of $9 \mathrm{~V}$, the luminance of the IOLEDs 1-3 was 778, 2493, and $6798 \mathrm{~cd} / \mathrm{m}^{2}$. Fig. 2(c) shows that at a given current density, the current efficiency of the IOLED 1 was slightly lower than that of the IOLED 2; The IOLED 3 gave higher current efficiency than the IOLEDs 1 and 2. This indicates that the hole-electron balance in the IOLED 3 was improved compared to those in the IOLEDs 1 and 2. The maximum current efficiencies for the IOLEDs $1-3$ were $1.7,1.8$, and $2.0 \mathrm{~cd} / \mathrm{A}$, respectively. Hence, it is conclusive that the combinatorial CBP: $\mathrm{MoO}_{3}$ and NPB: $\mathrm{MoO}_{3}$ provided increased IOLED performance than the single used NPB: $\mathrm{MoO}_{3}$ and CBP: $\mathrm{MoO}_{3}$.

\subsection{Understanding the hole current comparisons of the IOLEDs 1-3}

The hole current in the IOLEDs 1-3 is up to not only the conductivity of $p$-doped HTL, but also the $\phi_{\mathrm{B}}$ across the interface with undoped NPB. It is worth mentioning that the $\phi_{\mathrm{B}}$ often deviates from the Schottky-Mott limit [21], due to the formation of the interfacial dipole $(\Delta)$ expressed as

$$
\Delta=\left(1-\frac{1}{2}\left(\frac{1}{\varepsilon_{1}}+\frac{1}{\varepsilon_{2}}\right)\right)\left(C N L_{1}-C N L_{2}\right)_{\text {initial }},
$$

where $\varepsilon_{1}$ and $\varepsilon_{2}$ are the low frequency dielectric constants for organic materials, $\mathrm{CNL}_{1}$ and $\mathrm{CNL}_{2}$ represent their charge neutrality levels (i.e., chemical potentials).

Firstly, the $\phi_{\mathrm{B}}$ from NPB: $\mathrm{MoO}_{3}$ to NPB is estimated. Taking $\varepsilon_{\mathrm{NPB}} \sim 1.5$ and $\varepsilon_{\mathrm{NPB}: \mathrm{MoO} 3} \sim 20$ [21], the term of $\left(1 / \varepsilon_{1}+1 / \varepsilon_{2}\right)$ is estimated to be 0.72. Providing the CNLs for NPB: $\mathrm{MoO}_{3} \sim-4.9 \mathrm{eV}$ and NPB -4.2 eV [14, 21], Eq. (1) yields an interface dipole $\Delta=-0.45 \mathrm{eV}$, as shown in Fig. 3(i). Thus, the $\phi_{\mathrm{B}}$ from NPB: $\mathrm{MoO}_{3}$ to NPB is evaluated to be $0.45 \mathrm{eV}$. Next, the $\phi_{\mathrm{B}}$ from $\mathrm{CBP}: \mathrm{MoO}_{3}$ to the NPB interface is evaluated. Taking $\varepsilon_{\mathrm{NPB}} \sim 1.5$ and $\varepsilon_{\mathrm{CBP}: \mathrm{MoO} 3} \sim 20$, the term of $\left(1 / \varepsilon_{1}+1 / \varepsilon_{2}\right)$ is estimated to be 0.72. Providing the CNLs for CBP: $\mathrm{MoO}_{3} \sim-5.6 \mathrm{eV}$ [15] and NPB $-4.2 \mathrm{eV}$, Eq. (1) yields an interface dipole $\Delta=-0.90 \mathrm{eV}$, as shown in Fig. 3(ii). Thus, the $\phi_{\mathrm{B}}$ from CBP: $\mathrm{MoO}_{3}$ to NPB is approximated to be $0 \mathrm{eV}$. Then, the $\phi_{\mathrm{B}}$ from NPB: $\mathrm{MoO}_{3}$ to 
$\mathrm{CBP}: \mathrm{MoO}_{3}$ interface is estimated. Taking $\varepsilon_{\mathrm{NPB}: \mathrm{MoO} 3} \sim 20$ and $\varepsilon_{\mathrm{CBP}: \mathrm{MoO} 3} \sim 20$, the term of $\left(1 / \varepsilon_{1}+1 / \varepsilon_{2}\right)$ is estimated to be $\sim 0.1$. Providing the CNLs for CBP: $\mathrm{MoO}_{3} \sim-5.6 \mathrm{eV}$ and NPB: $\mathrm{MoO}_{3} \sim-4.9 \mathrm{eV}$, Eq.(1) yields an interface dipole $\Delta=0.67 \mathrm{eV}$, as shown in Fig. 3(iii). Thus, the $\phi_{\mathrm{B}}$ from NPB: $\mathrm{MoO}_{3}$ to $\mathrm{CBP}: \mathrm{MoO}_{3}$ is calculated roughly $0.23 \mathrm{eV}$, leaving the NPB: $\mathrm{MoO}_{3} / \mathrm{CBP}: \mathrm{MoO}_{3}$ heterojunction a quasi ohmic contact.

In terms of the $p$-doped-HTL conductivity, there is a decreasing order of IOLED 1 (20 nm NPB: $\left.\mathrm{MoO}_{3}\right)>$ IOLED 3 (10 nm CBP: $\mathrm{MoO}_{3}$ and $10 \mathrm{~nm} \mathrm{NPB:MoO}$ )>IOLED 2 (20 nm CBP: $\mathrm{MoO}_{3}$ ). On the other hand, as far as the $\phi_{\mathrm{B}}$ is concerned, there is a decreasing order of IOLED $1(0.45 \mathrm{eV})>$ IOLED $3(0.23 \mathrm{eV})>$ IOLED $2(0 \mathrm{eV})$. Consequently, it can be concluded that the complementary combination of CBP: $\mathrm{MoO}_{3}$ and NPB: $\mathrm{MoO}_{3}$ can offer the simultaneous optimization of conductivity and $\phi_{\mathrm{B}}$ relative to the single $\mathrm{CBP}: \mathrm{MoO}_{3}$ and $\mathrm{NPB}: \mathrm{MoO}_{3}$, answering for the increased performance of the IOLED 3 than the IOLEDs 1 and 2. The observation that the IOLED 2 showed better performance than the IOLED 1 was because the advantage in $\phi_{\mathrm{B}}$ of the IOLED 2 over the IOLED 1 markedly overwhelmed the advantage in conductivity of the IOLED 1 over the IOLED 2.

\subsection{The configuration of $\mathrm{CBP}: \mathrm{MoO}_{3}$ and $\mathrm{NPB}: \mathrm{MoO}_{3}$ in the IOLEDs}

Fig. 4(a) shows the current density versus voltage curves for the IOLEDs 3-5. From 4 to $9 \mathrm{~V}$, the IOLEDs 3 and 4 showed much improved $I-V$ characteristics than

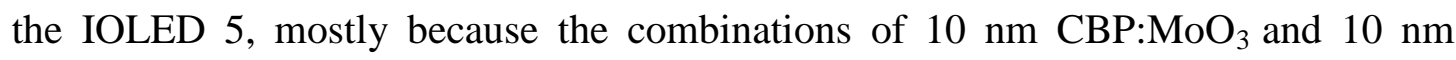
$\mathrm{NPB}: \mathrm{MoO}_{3}$ and of $5 \mathrm{~nm} \mathrm{CBP}: \mathrm{MoO}_{3}$ and $15 \mathrm{~nm} \mathrm{NPB}: \mathrm{MoO}_{3}$ were more conductive than that of $15 \mathrm{~nm} \mathrm{CBP}: \mathrm{MoO}_{3}$ and $5 \mathrm{~nm} \mathrm{NPB}: \mathrm{MoO}_{3}$. Due to the higher conductivity of the combined $5 \mathrm{~nm} \mathrm{CBP}: \mathrm{MoO}_{3}$ and $15 \mathrm{~nm} \mathrm{NPB}: \mathrm{MoO}_{3}$ than that of the combined $10 \mathrm{~nm}$ CBP: $\mathrm{MoO}_{3}$ and $10 \mathrm{~nm}$ NPB: $\mathrm{MoO}_{3}$, the IOLED 4 gave improved $I-V$ characteristics than the IOLED 3 at lower driving voltages, but the $I-V$ characteristics for these two devices became nearly same at higher driving voltages. At a driving voltage of $9 \mathrm{~V}$, the current densities of the IOLEDs 3-5 were 384.3, 358.6, and 154.9 $\mathrm{mA} / \mathrm{cm}^{2}$, respectively. As seen in Fig. 4(b), the IOLEDs 3 and 4 were much brighter than the IOLED 5. At a driving voltage of $9 \mathrm{~V}$, the luminance of the IOLEDs 3-5 was 6798, 6082, and $2685 \mathrm{~cd} / \mathrm{m}^{2}$, respectively. Fig. 4(c) indicates that there was a decrease of current efficiency in the order of IOLED 3>IOLED 4>IOLED 5. The maximum 
current efficiencies for the IOLEDs 3-5 were 2.0, 1.8, and $1.7 \mathrm{~cd} / \mathrm{A}$, respectively, suggesting that the configuration of $10 \mathrm{~nm} \mathrm{CBP}: \mathrm{MoO}_{3}$ and $10 \mathrm{~nm} \mathrm{NPB}: \mathrm{MoO}_{3}$ gave rise to the improved hole-electron balance.

\section{Conclusions}

The IOLEDs employing $p$-doped HTL play an important role in active-matrix flat-panel display, so it is of significance to improve their performance in practical

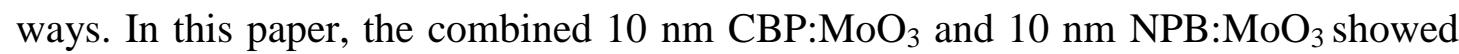
improved hole current into the NPB and thereby the performance of IOLED, relative to the single $20 \mathrm{~nm}$ CBP: $\mathrm{MoO}_{3}$ and $20 \mathrm{~nm}$ NPB: $\mathrm{MoO}_{3}$. Hence, the combination of the two $p$-doped HTLs can be thought useful to unlock the merits of $p$-doped HTLs in the IOLEDs, much benefiting their advance towards the low-cost commercialization. The future work will focus on the power loss optimization of the phosphorescent IOLEDs via using this concept to enhance hole current into the 4, 4', 4"'-tris(carbazol-9-yl)-triphenylamine.

\section{Acknowledgements.}

The authors are grateful for the financial support from the National Science foundations of Hebei province (Grant No. E2013202119).

\section{References.}

[1] X. Zhou, M. Pfeiffer, J.S. Huang, J. Blochwitz-Nimoth, D.S. Qin, A. Werner, J. Drechesel, B. Maennig, K. Leo, Low-voltage inverted trans-parent vacuum deposited organic light-emitting diodes using electrical doping, Appl. Phys. Lett. 81 (2002) 922-924.

[2] P.E. Burrows, G. Gu, S.R. Forrest, E.P. Vicenzi, T.X. Zhou, Semitransparent cathodes for organic light emitting devices, J. Appl. Phys. 87 (2000) 3080-3085.

[3] S.Y. Chen, T.Y. Chu, J.F. Chen, C.Y. Su, C.H. Chen, Stable inverted bottom-emitting organic electroluminescent devices with molecular doping and morphology improvement, Appl. Phys. Lett. 89 (2006) 053518.

[4] T. Xiong, F.X. Wang, X.F. Qiao, D.G. Ma, Cesium hydroxide doped 
tris-(8-hydroxyquinoline) aluminum as an effective electron injection layer in inverted bottom-emission organic light emitting diodes, Appl. Phys. Lett. 92 (2008) 263305.

[5] C.H. Yun, H. Cho, H. Kang, Y.M. Lee, Y. Park, S. Yoo, Electron injection via pentacene thin films for efficient inverted organic light-emitting diodes, Appl. Phys. Lett. 95 (2009) 053301.

[6] M. Thomschke, S. Hofmann, S. Olthof, M. Anderson, H. Kleemann, M. Schober, B. Lüssem, K. Leo, Improvement of voltage and charge balance in inverted top-emitting organic electroluminescent diodes comprising doped transport layers by thermal annealing, Appl. Phys. Lett. 98 (2011) 083304.

[7] D.S. Qin, M.X. Wang, Y.H. Chen, L. Chen, G.F. Li, Electron injection via doped p-n heterojunction for inverted organic light emitting diodes, Phys. Scr. 89 (2014) 015802 .

[8] D.S. Qin, L. Chen, Y.H. Chen, J.S. Liu, G.F. Li, W. Quan, J.D. Zhang, D.H. Yan, Enhanced performance in inverted organic light emitting diode assisted by an interlayer of crystalline and n-doped 1,4,5,8-naphthalene-tetracarboxylic-dianhydride. Phys. Solidi Status A 209 (2012) 790-794.

[9] C.R. Cheng, Y.H. Chen, D.S. Qin, W. Quan, J.S. Liu, Inverted bottom-emission organic light emitting diode using two n-doped layers for the enhanced performance, Chin. Phys. Lett. 27 (2010) 117801.

[10] D.S. Qin, J.S. Liu, Y.H. Chen, C.R. Cheng, W. Quan, Inverted bottom-emission organic light emitting diodes using $\mathrm{MoO}_{3}$ for both hole and electron injections, Phys. Solidi Status A, 208 (2011) 1976-1979.

[11] C.H. Gao, X.Z. Zhu, L. Zhang, D.Y. Zhou, Z.K. Wang, L.S. Liao, Comparative studies on the inorganic and organic p-type dopants in organic light-emitting diodes with enhanced hole injection, Appl. Phys. Lett. 102 (2013) 153301.

[12] J.H. Lee, D.S. Leem, H.J. Kim, J.J. Kim, Effectiveness of p-dopants in an organic hole transporting material, Appl. Phys. Lett. 94 (2009) 123306.

[13] K. Walzer, B. Maennig, M. Pfeiffer, K. Leo, Highly efficient organic devices 
based on electrically doped transport layers, Chem. Rev. 107 (2007) 1233-1271.

[14] M. Kröger, S. Hamwi, J. Meyer, T. Riedl, W. Kowalsky, A. Kahn, P-type doping of organic wide band gap materials by transition metal oxides: A case-study on Molybdenum trioxide, Org. Electron. 10 (2009) 932-938.

[15] S. Hamwi, J. Meyer, T. Winkler, T. Riedl, W. Kowalsky, P-type doping efficiency of $\mathrm{MoO}_{3}$ in organic hole transport materials, Appl. Phys. Lett. 94 (2009) 253307.

[16] S.W. Tsang, Z.H. Lu, Y. Tao, Engineering carrier transport across organic heterojunctions by interface doping, Appl. Phys. Lett. 90 (2007) 132115.

[17] M.G. Helander, Z.B. Wang, J. Qiu, M.T. Greiner, D.P. Puzzo, Z.W. Liu, Z.H. Lu, Chlorinated indium tin oxide electrodes with high work function for organic device compatibility, Science 332 (2011) 944-947.

[18] D.S. Qin, J.S. Liu, Y.H. Chen, W. Quan, G.F. Li, Increased performance in the oranic light-emitting diode employing two p-doped hole transport layer, Semicond. Sci. Technol. 27 (2012) 045012.

[19] T.J. Park, S.Y. Kim, W.S. Jeon, J.J. Park, R. Pode, J. Jang, J.H. Kwon, Electrical characterization of $\mathrm{n}$ - and p-doped hole and electron only organic devices, J. Nanosci. Nanotechnol. 8 (2008) 5606-5609.

[20] G.H. Xie, Y.L. Meng, F.M. Wu, C. Tao, D.D. Zhang, M.J. Liu, Q. Xue, W. Chen, Y. Zhao, Very low turn-on voltage and high brightness tris-(8-hydroxyquinoline) aluminum-based organic light-emitting diodes with a MoOx p-doping layer, Appl. Phys. Lett. 92 (2008) 093305.

[21] A. Kahn, W. Zhao, W.Y. Gao, H. Vazquez, F. Flores, Doping-induced realignment of molecular levels at organic-organic heterojunctions, Chem. Phys. 325 (2006) $129-137$. 


\section{Captions.}

Fig. 1. The energetic parameters for NPB: $\mathrm{MoO}_{3}$ and $\mathrm{CBP}: \mathrm{MoO}_{3}$. The WF, LUMO, and VL stand for work function, lowest unoccupied molecular orbital, and vacuum level, respectively. The horizontal dashed lines represent the Fermi levels.

Fig. 2. The $I-V$ (a), luminance versus voltage (b), and current efficiency versus current density (c) characteristics of IOLEDs 1-3. Note that, all of IOLEDs 1-5 gave nearly same electroluminescent spectra, as shown in the inset of Fig. 2(c).

Fig. 3. The schematic diagrams describing the energy level alignments in the NPB: $\mathrm{MoO}_{3} / \mathrm{NPB}$ (i), CBP: $\mathrm{MoO}_{3} / \mathrm{NPB}$ (ii), and NPB: $\mathrm{MoO}_{3} / \mathrm{CBP}: \mathrm{MoO}_{3}$ (iii) interfaces. The VL, $\mathrm{E}_{\mathrm{F}}$, and LUMO stand for vacuum level, Fermi level, and lowest unoccupied molecular orbital, respectively. The $\phi_{\mathrm{B}}$ across the NPB: $\mathrm{MoO}_{3} / \mathrm{NPB}$, CBP: $\mathrm{MoO}_{3} / \mathrm{NPB}$, and NPB: $\mathrm{MoO}_{3} / \mathrm{CBP}: \mathrm{MoO}_{3}$ heterojunctions was calculated to be $0.45,0$, and $0.23 \mathrm{eV}$, respectively. Note that, the band bending is neglected at the interfaces for the simplicity.

Fig. 4. The $I-V$ (a), luminance versus voltage (b), and current efficiency versus current density (c) characteristics of IOLEDs 3-5. 
Fig. 1. Song Jin et al.,

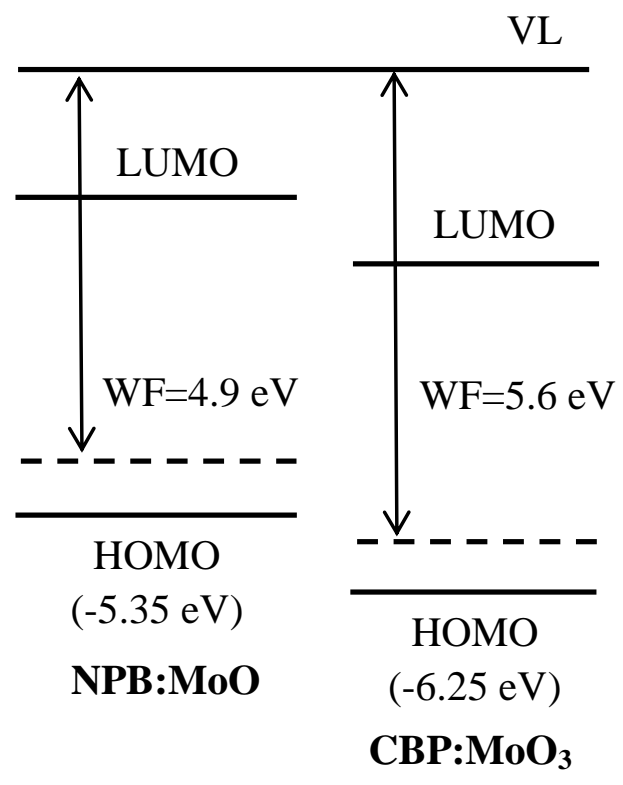


Fig. 2. Song Jin et al.,
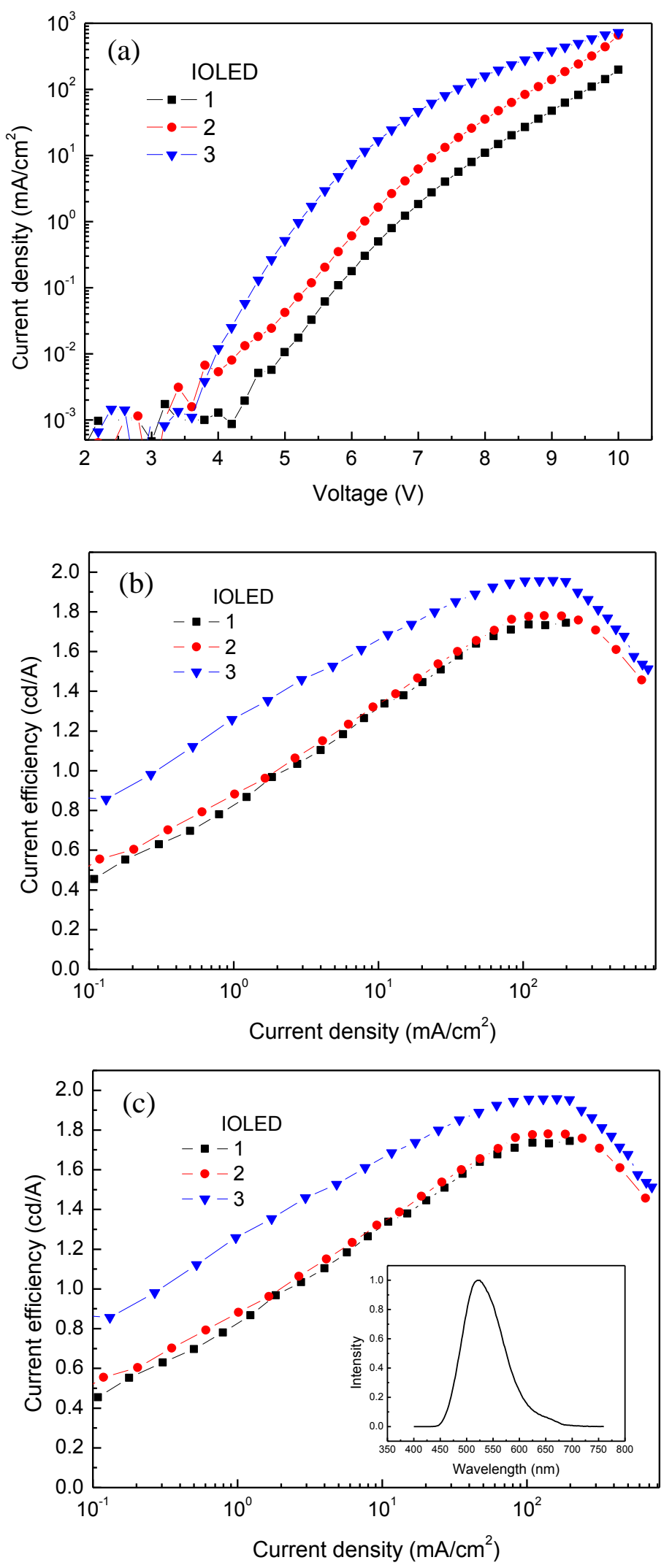
Fig. 3. Song Jin et al.,

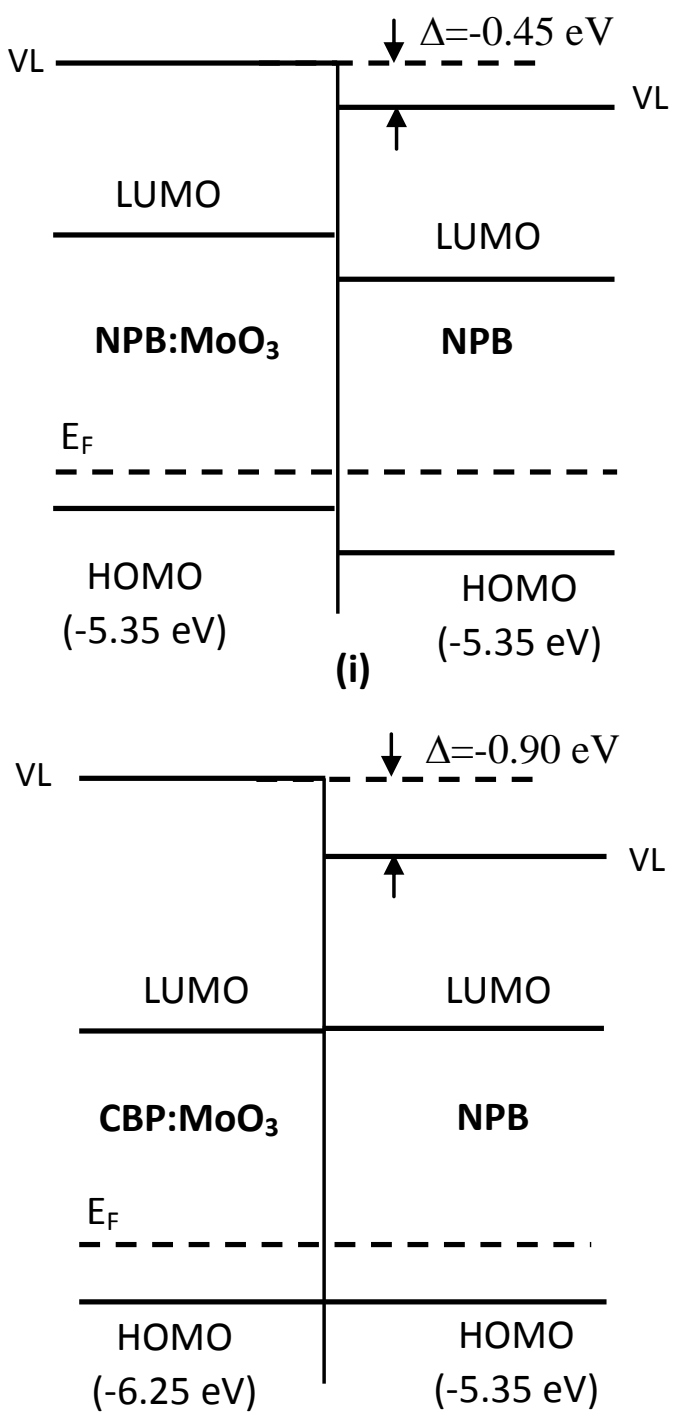

(ii)

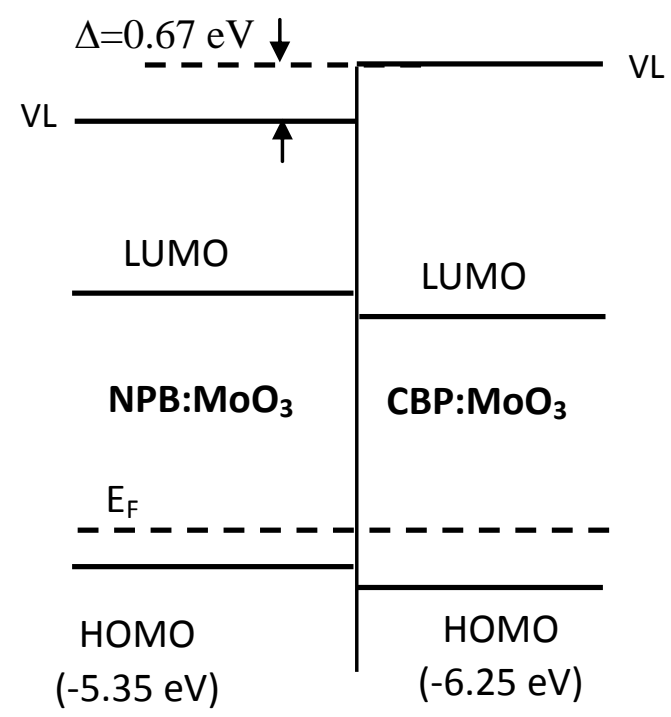

(iii) 
Fig. 4. Song Jin et al.,
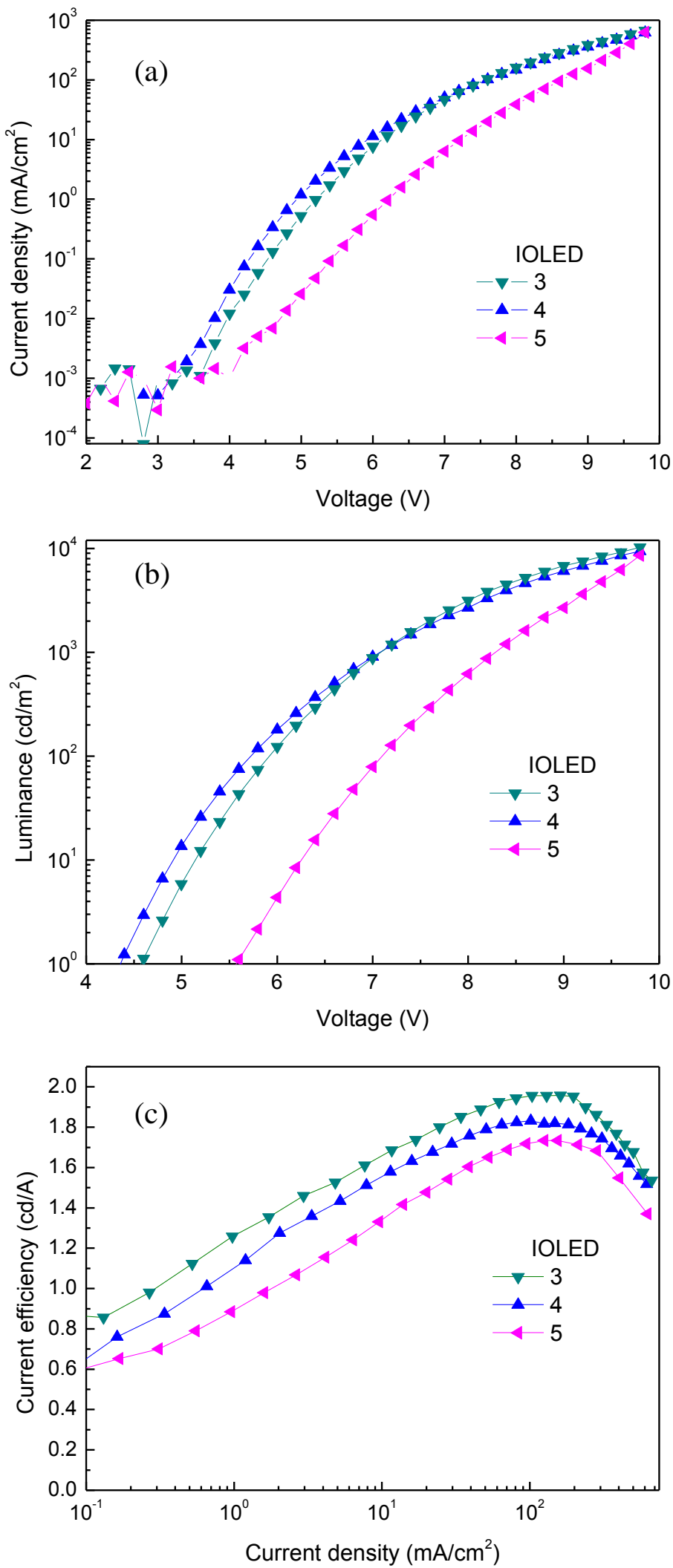